THE PRELUDE TO THE MIGRAINE ATTACK. W. K. AMERY, A. WAUKIER, editores. Ưm volume com 213 páginas $(12,5 \times 22,5 \mathrm{~cm})$. Baillière Tindall, 1986.

Este livro é o fruto de Simpósio Internacional, realizado em 1985 pela Sociedade Belga de Enxaqueca e pela Jansen Research Foundation. A hemicrânia, enigmática afeçăo paroxística, ainda se reveste de muitas indagações. Diversas áreas de pesquisa tēm se desenvolvido, procurando responder a aspectos do problema. Entre eles, destaca-se o estudo de fatores que agem como «gatilho». Três artigos abordam esse tema. Dalessio e col. revêem determinantes endógenos e psicológicos; Debney e col., fatores físicos; inventário de substâncias que eventualmente exercem papel de gatilho é apresentado por olesen. Parte interessante desse livro é reservada para fenômenos premonitórios da enxaqueca. Blau excursiona pelos sintomas cerebrais, alimentares, de equilibrio eletrolitico o musculares, os quais são distinguidos em fenómenos excitatórios e inibitórios; chega a concluir que a enxaqueca $\doteq$ processo primário com respostas vasculares secundárias. Harding e Gale, Investigam os sintomas precoces de hipóxia e da hipoglicemia cerebrais. Um papel da dopamina na patogenia da enxaqueca é sugerido, pela semelhança que se observa entre os sintomas da enxaqueca $\geqslant$ os efeitos clínicos dos agentes dopaminérgicos, assim como pelos uchados bioquimicos e pelos efeitos do tratamento precoce com o domperidone, que $e$ bloqueador dos receptores dopaminérgicos periféricos (Amery e col.). A terceira parte do livro se destina ao estudo da aura da enxaqueca, em que săo revistas suas caracteristicas clínicas (Lera). Capitulo sobre alucinacóes e enxaquecas é escrito por Diamond e col.; os fenòmenos alucinatórios são classificados em alucinações especificas (visuais, escotomas simples, aspectos de fortificaçāo ou fotopsias), em alteraçōes de humor (em que sensaçōes «forçadas», eventualmente desagradáveis, precedem a crise) e em alteracōes da funçåo intelectual. Cliford Rose se incumbe do estudo dos equivalentes migranosos, isto é, aqueles distúrbios transitórios que substituem o ataque, mas em que falta cefaléia. Entre esses distúrbios inclui a amnésia global transitória, pelo menos em algumas de suas formas, a enxaqueca cardiaca (dor precordial, pseudo-angina enxaquecosa ou angina innocens), enxaqueca abdominal (vômitos cíclicos, sindrome periódica ou dores de crescimento). Entre esses vários tipos de aura, os escotomas cintilantra e a sindrome digito-lingual såo as formas mais frequientes. Atribui-se classicamente a aura da enxaqueca a fenômenos de excitaçāo e extinçāo, ambos caracterizados por certo alastramento, Provavelmente, origina-se do córtex cerebral a até recentemente considerava-se a isquemia localizada como seu mecanismo mais provável. Spierings, em revisão sobre a patogenia da aura enxaquecosa, a favor dessa teoria de hỉóxia tissular, invoca dois mecanismos básicos: a vasoconstrição arterial e um aumento dos circuitos artério-venosos. Uma terceira teoria, também defendida por Spierings, atribui os sintomas a processo conhecido como depressão alastrante ou fenômeno de Leão. O próprio Aristides Leão, no capítulo seguinte responde à indagaçåo: o que é a depressão alastrante cortical? Os trabalhos de Moskowitz e seus colaboradores são estudados em capítulo especial em que se salienta a relevância das projeçóes dos neurônios trigeminais nas cefaléias vasculares. Referem-se à terapêutica da enxaqueca os três últimos capitulos: efeitos de drogas sobre a depressão alastrante cortical (Marrannes e col.), sobre a aura (Lous) e medidas utilizáveis durante a aura.

Em resumo, é muito interessante este volume, focalizando especificamente os preàmbulos e o desencadear dos ataques enxaquecosos, de forma a estimular as investigaçöes sobre os mecanismos desta fase precoce das enxaquecas. Provavelmente a compreensão dessas fases iniciais do ataque ocasionará atitudes mais racionais para a terapêutica da própria afecçăo.

\title{
ROBERTO MELARAGNO FILHO
}

CLINICAL DISORDERS OF MEMORY. AMAN U. KHAN. Um volume com 272 páginas (16 x 25cm). Plenum Medical Books, New York, 1986.

Este livro, da série Critical Issues in Psychiatry, reflete os estudos e a experiência da Escola de Medicina da Universidade de Illinois e compreende 13 capitulos. «A Natureza da Memória», o primeiro deles, introduz o assunto, cuja relevância é dispensável realçar. Com efeito, a memória é essencial para a retençāo do aprendizado e, quando deficitária, novos aprendizados são comprometidos, assim como a realizaçâo de hábitos previamente aprendidos deteriora-se. Os gregos representavam a memória como a deusa Mnemósine, mãe de nove filhas, as Musas, patronas de várias artes. A despeito de sua importância, por cerca de 80 anos, após os trabalhos fundamentais de Ebbinhaus (1850-1909), a memória permaneceu assunto de interesse dos psicólogos. De um ponto de vista geral. a memória 
pode ser conceituada como o armazenamento de potenciais comportamentais aprendidos através do tempo. Pode agora também ser compreendida como o resultado de modificaçōes funcionais persistentes do SNC induzidas nor influxos ambientais e por atividades do organismo. A neurobiologia da memória é, estudada e as indagações formuladas pelos psicólogos sāo investigadas em bases biológicas. $O$ capítulo 2 é dedicado à avaliação da memória, por vários grupos de teste. Nenhum processo é ideal e amplamente satisfatório; nāo há testes biológicơs que indiquem déficit de memória. No capitulo seguinte, discriminam-se as drogas que poderiam exercer influência no aprendizado e na memória: inventário de agentes farmacológicos é acompanhado de estudo crítico sobre os efeitos putativos de cada um deles. O efeito do álcool no comprometimento da memória ê tema de um capitulo específico; de fato, o SNC é um dos órgãos mais sensiveis a seus efeitos tóxicos e as atrofias cerebrais progressivas, verificadas pelo CT em alcóolatras crônicos, são analisadas. Os neurotransmissores, neuromoduladores e hormônios têm sido exaustivamente estudados quanto ao seu papel nos processos mnésicos: breve revisáo é dedicada ao papel da noradrenalina, da dopamina, do sistema serotonérgico e de certos hormônios. O capitulo 6, «Memória nas Doenças Degenerativas do Sistema Nervoso», inicia-se pela doença de Alzheimer, seguindo-se a doenca de Pick antes de considerar outras.

A memória nos acidentes vasculares cerebrais é assunto do capitulo seguinte. No encéfalo, a exclusăo de área ou áreas de seu parênquima pode condicionar sofrimento em vários aspectos, inclusive nos complexos processos da memória. Assim, são revistas sucessivamente as isquemias crônicas do encéfalo, o ataque isquêmico-transitório, os grandes enfartes cerebrais e a demência dos multi-enfartes. A memória habitualmente é comprometida em infeccões crônicas do SNC, entre as quais Khan enumera e estuda a sífilis do SNC, infeccōes virais crônicas, a poliencefalite esclercsante subaguda, a leucoencefalopatia multifocal progressiva, as encefalites espongiformes progressivas e sequelas a longo prazo de meningites bacterianas da infância. Doenças crônicas sistêmicas que podem ocasionar dano cerebral com dano comprometimento da memória são analisadas, seguindo-se o estudo de distúrbios de memória no trauma craniano. Menção especial é feita para as desordens funcionais da memória, a principiar pelas ocasionadas pela depressåo (pseudodemência). Outras afeccões psiquiátricas podem se apresentar sob forma de desordens mnesicas sendo consideradas esquisofrenia, autismo e várias desordens dissociantes. Menção é também feita a aspectos não necessariamente patológicos, como pequenas lacunas de memória, memória do sonho e a amnésia do sonho. o capítulo 12 é de transcendental importância prática: as alterações da memória que acompanham o envelhecimento. $\overline{\mathbf{E}}$ conceito habitualmente aceito a redução da memória paralelamente ao envelhecimento. Entretanto, avaliação para se determinar a quantidade e o tipo de déficit da memória do idoso não chegou a resultados definitivos.

Encerra este livro o capitulo concernente às estratégias para o tratamento das alteracões de memória. \& capítulo crítico, em que Khan realça o valor do treinamento das habilidades cognitivas. Evidentemente, essas estratégias năo se revestem de maior valor em pacientes com doenças cerebrais. «Clinical Disorders of Memory» é recomendado para neurologistas, internistas, psiquiatras e geriatras.

ROBERTO MELARAGNO FILHO

SLEEP AND ITS DISORDERS IN CHILDREN. C. GUILLEMINAULT, editor. Um volume com 216 páginas. Raven Press, New York, 1987.

Diferentes especialistas tratam neste livro de temas atuais e importantes sobre o sono na infância e adolescência. Oferecem visåo geral da fisiologia do sono $\theta$ da respiração, dados normativos do polissonograma no neonato e sobre patologias mais comuns na infáncia. No primeiro capitulo, encontramos excelente revisảo dos aspectos polêmicos do estagiamento do sono nos primeiros meses de vida, incluindo os prematuros. William Dement e seus colaboradores escrevem sobre o sono na pré-adolescência e adolescência, levantando hipoteses provocativas sobre os desvios fisiológicos do sono e suas consequiências, A fisiologia respiratória durante $\curvearrowright$ sono é detalhada em capitulo baseado em revisāo bibliografica extensa. As parassonias são motivo de dois capitulos, ambos com dados epidemiológicos interessantes.

Os distúrbios do sono propriamente ditos são descritos seguindo as normas da Associacăo dos Centros de Distúrbios do Sono. Estes capitulos são escritos pelo editor, Christian Guilleminault, que ressalta entre outros aspectos os achados de apnéia como causa importante da sonolência na infância. O autor chama a atenção para a pequena incidência da narcolepsia em crianças abaixo de 11 anos de idade e, também, para possiveis dificuldades 
diagnósticas desta patologia na infância, com base nos dados da polissonografia e do teste da latência múltipla. A relaçăo entre apnéia e a síndrome de morte súbita na infância (SIDS) é bem discutida, sendo salientado que, se apnéia do sono não explica a maior parte dos casos de SIDS, esta tem grande importância por si mesma pela alta morbidade que acarreta. Os dois últimos capitulos são dedicados a aspectos do sono em doenças neurológicas, enfatizando-se os achados em deficientes mentais e nas epilepsias.

ADEMIR BAPTISTA DA SILVA

\section{ACADEMIA BRASILEIRA DE NEUROLOGIA}

\section{MENSAGEM DO PRESIDENTE}

Meus prezados amigos,

Aproxima-se a data da realização do XIII Congresso Brasileiro de Neurologia: 24-29 de setembro de 1988. Conseguimos para sede deste evento o Centro de Convenções Anhembi, o local mais adequado que temos.

Numerosos especialistas estrangeiros estarão presentes mostrando-nos o avanço de nossa especialidade nos centros mais adiantados do mundo. Numerosos especialistas nacionais estarão também presentes, mostrando sua experiência nos mais diversos temas neurológicos.

No sentido de intensificarmos os laços com especialidades co-irmäs, colocamos em nosso programa temas de neurofisionologia clinica, fisiatria, fonoaudiologia e foniatria.

Essa ampla abordagem será feita em forma de Simpósios, Mesas Redondas, Conferências, Sessões de Video, Temas Livres e Sessões de Poster.

A programação social será bastante acolhedora.

Tudo isso de nada adiantará se não tivermos o apoio dos senhores no sentido de divulgarem este evento em seu meio e no sentido de estarem aqui para comemorarmos juntos mais esta demonstração de maturidade científica de nossa Academia.

Meus amigos, conto com todos os senhores! Até o nosso XIII Congresso Brasileiro de Neurologia. 